\title{
Turismo e Desenvolvimento Regional - Uma perspetiva do Turismo em Espaço Rural na Serra do Marão, em Portugal
}

\section{Tourism and Regional Development - A perspective of rural tourism in the Serra do Marão in Portugal}

\author{
Ivo Dinis Oliveira (OLIVEIRA, I. D.)* e Francisco Diniz (DINIZ, F.)**
}

RESUMO - O objetivo do presente estudo consistiu em efetuar uma explanação dos modelos de desenvolvimento baseados em turismo, adequados a áreas rurais, interiores e periféricas. Neste sentido, foram verificadas as perspetivas de desenvolvimento endógeno e sustentável e caracterização do Turismo no Espaço Rural (TER). Constatouse a importância do marketing turístico e procurou-se efetuar um trabalho de investigação, enfocando numa unidade turística do Marão (Portugal), que revelasse qual o impacto do Turismo no desenvolvimento da região de Trás-os-Montes e Alto Douro, bem como avaliar do valor percebido global da experiência do turista. A metodologia utilizada foi o inquérito por questionário aos visitantes da unidade de Turismo Rural em 2009.

Palavras-chave: Turismo; Desenvolvimento Regional; Turismo em Espaço Rural; Marketing Turístico.

ABSTRACT - The purpose of this study was to make an explanation of the models of development based on tourism, appropriate to rural areas, inland and remote areas. In this sense it was verified the prospects for sustainable and endogenous development and characterization of Tourism in Rural Areas. It was observed the importance of tourist marketing and it was sought to make a research work, focusing on a tourism unit at Marão (Portugal), which revealed what was the impact of the tourism on development of the region Trás-os-Montes and Alto Douro, as well as evaluated the perceived global value of the tourist experience. The methodology used was the questionnaire survey to visitors in the Rural Tourism unit in 2009.

Key words: Tourism; Regional Development; Rural Tourism; Tourist Marketing.

\footnotetext{
*Formação: Licenciatura em Economia - Faculdade de Economia do Porto, Mestrado em Economia das Organizações - Universidade de Trás-os-Montes e Alto Douro, Doutorado em Gestão - Universidade de Trás-os-Montes e Alto Douro. Investigador vinculado no CEPESE - Centro de Estudos da População, Economia e Sociedade. Professor Universitário vinculado na Universidade Europeia e no ISLA-Instituto Politécnico de Gestão e Tecnologia. Endereço físico para correspondência: Universidade Europeia Campus LISPOLIS. Rua Laura Aires 4, 1600-510 - Lisboa - Portugal. E-mail: ivodinisoliveira@gmail.com; ivo.oliveira@ universidadeeuropeia,pt
}

** Formação: Licenciatura em Organização e Gestão de Empresas , (Instuto Superior de Economia e Gestão, Universidade de Lisboa), Mestrado em Gestão da empresa Agrícola, Universide de Trás-osMontes e Alto Douro). Doutoramento em Economia (Universidade de Trás-os-Montes e Alto Douro). Membro do Centro de Investigação CETRAD - UTAD - Universidade de Trás-os-Montes e Alto Douro. Endereço físico para correspondência: Rua 1, n. 14, Losa Prado, 4730-463 - Prado Vila Verde Portugal. E-mail: Fdiniz54@gmail.com; fdiniz@utad.pt 


\section{INTRODUÇÃO ${ }^{1}$}

O turismo rural é importante para desenvolver as economias dos meios rurais (PATO, 2012), aumentando a sua viabilidade económica (EURICO; OLIVEIRA, 2015), estimulando a sua regeneração social e as condições de vida das comunidades rurais (KASTENHOLZ, 2010), sendo este efeito tanto mais forte, quanto mais conseguir endogeneizar os recursos, a história, as tradições e a cultura de cada região (NEVES, 2008).

O Turismo em Espaço Rural moderno está orientado para uma visão holística do universo rural e da valorização dos seus diferentes elementos (DIMITROVSKI et al., 2012), implicando uma gestão profissionalizada, orientação para as necessidades do cliente e qualidade na prestação de serviços (RIBEIRO, 2003), ainda que mantendo a importância da preservação das características dos territórios locais e a reduzida escala de atividade (MATEUS, 2017).

O mercado do turismo caracteriza-se por ser uma atividade horizontal com empresas relacionadas a montante e a jusante, atuando de forma interligada. (TRINDADE, 1998).

A principal motivação para a criação de estabelecimentos de Turismo em Espaço Rural (TER), nem sempre é o fator económico, mas sim a preocupação na reabilitação dos bens adquiridos através de heranças familiares (SILVA, 2006). Na maioria trata-se de negócios familiares, o que faz com que muitos proprietários acumulem funções, não só referentes ao próprio negócio, como também em relação a outra profissão que desempenhem em paralelo (KLEIN et al., 2014).

A visão traçada para o turismo no Norte de Portugal assenta no vasto conjunto de atributos que marcam o Norte de Portugal como ser o primeiro destino de Turismo da Natureza e Rural do país, assente numa rede de áreas protegidas e rurais de elevado valor natural e paisagístico (TURISMO DE PORTUGAL, 2015).

\footnotetext{
${ }^{1}$ AGRADECIMENTOS:

Este trabalho é financiado por: Fundos Europeus Estruturais e de Investimento, na sua componente FEDER, através do Programa Operacional Competitividade e Internacionalização (COMPETE 2020) [Projeto n 006971 (UID/SOC/04011); Referência do Financiamento: POCI-01-0145-FEDER-006971]; e por Fundos Nacionais através da FCT - Fundação para a Ciência e a Tecnologia, no âmbito do projeto UID/SOC/04011/2013.
} 
Apesar da dimensão ainda relativamente pequena deste segmento, desde 2003 registra-se um crescimento anual médio próximo dos $7 \%$, claramente acima da média de procura de alojamento turístico no país, segundo o Instituto Nacional de Estatística (DINIS, 2017).

O potencial é evidente: o turismo em espaço rural em Portugal pode quadruplicar numa década, destacando-se o papel "muitíssimo importante" do alojamento local para "aproximar as pessoas de experiências únicas" nestes territórios (MATEUS, 2017). Entre os motivos que explicam o crescimento do TER, encontram-se fatores como: a crescente valorização da paz e tranquilidade (MARQUES, 2005); aumento da consciência ecológica; crescente interesse na gastronomia especializada; rejeição da massificação, com canalização das disponibilidades financeiras e de tempo livre para opções mais autênticas e genuínas (KASTENHOLZ; LIMA, 2011); em regiões mais rurais, onde as paisagens, costumes, tradições e cultura se mantenham intactas (CAVACO, 1996).

Assim, desenvolvimento endógeno (DINIZ; GERRY, 2002) pressupõe a motivação dos participantes com o fim de pôr em marcha um processo de mudança que faça evoluir determinada comunidade para um estado qualitativamente superior, isto é, com melhoria das condições de vida (DINIZ F, 2006). Obtem-se desta forma uma comparação clara entre os modelos Neoclássico, Keynesiano e de desenvolvimento endógeno (QUADRO 1).

\begin{tabular}{l|l|l|l}
\hline $\begin{array}{c}\text { MODELO } \\
\text { hegemonia } \\
\begin{array}{c}\text { (H) ou } \\
\text { influência } \\
\text { (I) }\end{array}\end{array}$ & $\begin{array}{c}\text { A. NEOCLÁSSICA } \\
\text { décadas 50/60 (H) e 90/00 (H) }\end{array}$ & $\begin{array}{c}\text { B. KEYNESIANA } \\
\text { décadas 60 (I) 70/80 (H) }\end{array}$ & \multicolumn{1}{c}{$\begin{array}{c}\text { C. ENDÓGENA } \\
\text { décadas 80/90 (I) }\end{array}$} \\
\hline $\begin{array}{l}\text { PRINCÍPIO } \\
\text { BÁSICO }\end{array}$ & $\begin{array}{l}\text { Predominantemente o livre } \\
\text { funcionamento do mercado. }\end{array}$ & $\begin{array}{l}\text { O livre funcionamento do } \\
\text { mercado, complementado, } \\
\text { estrategicamente, pela } \\
\text { intervenção do estado. }\end{array}$ & $\begin{array}{l}\text { Funcionamento do mercado } \\
\text { relativamente livre, } \\
\text { complementado, } \\
\text { estrategicamente, pela } \\
\text { promoção por parte do poder } \\
\text { central e/ou regional, de } \\
\text { iniciativas económicas e } \\
\text { sociais ao nível da comunidade } \\
\text { local. }\end{array}$ \\
\hline
\end{tabular}


... Continuação.

\begin{tabular}{|c|c|c|c|}
\hline $\begin{array}{l}\text { MECANIS- } \\
\text { MO BÁSICO }\end{array}$ & $\begin{array}{l}\text { A acumulação de capital. } \\
\text { Privilegia o espaço como um } \\
\text { todo e acredita que o } \\
\text { desenvolvimento regional vem } \\
\text { por arrasto. Admite a } \\
\text { desigualdade como um mal } \\
\text { necessário ao processo de } \\
\text { desenvolvimento. }\end{array}$ & $\begin{array}{l}\text { Combinação óptima entre } \\
\text { aumentos da competitividade } \\
\text { da produção regional, por um } \\
\text { lado, e o melhoramento da } \\
\text { qua- } \\
\text { lidade de vida regional, por } \\
\text { outro, muito embora a } \\
\text { competitividade esteja } \\
\text { considerada o factor } \\
\text { determinante. Promoção de } \\
\text { uma distribuição } \\
\text { interterritorial, mais } \\
\text { equilibrada do valor } \\
\text { acrescentado. } \\
\end{array}$ & $\begin{array}{l}\text { Emprego mais pleno dos } \\
\text { recursos locais (especialização } \\
\text { local em determinadas } \\
\text { matérias primas e produtos, } \\
\text { força de trabalho, know-how e } \\
\text { ambientes locais), e o aumento } \\
\text { da sua produtividade; a } \\
\text { retenção de mais valor } \\
\text { acrescentado no local; a } \\
\text { preservação e a valorização } \\
\text { dos valores da cultura e dos } \\
\text { costumes locais. }\end{array}$ \\
\hline $\begin{array}{l}\text { ENFOQUE } \\
\text { TEÓRICO }\end{array}$ & $\begin{array}{l}\text { A persistência de assimetrias } \\
\text { regionais é devida às } \\
\text { imperfeições nos mercados, } \\
\text { sobretudo as rigidezes } \\
\text { institucionais, que limitam a } \\
\text { mobilidade interregional de } \\
\text { factores (em particular do } \\
\text { trabalho), distorcem os preços, } \\
\text { e fomentam ineficiência e não } \\
\text { subaproveitamento de } \\
\text { potencialidades. }\end{array}$ & $\begin{array}{l}\text { Assimetrias na mobilidades } \\
\text { espacial do capital, o que faz } \\
\text { com que custos de transacção } \\
\text { ligados à distância física } \\
\text { acentuem desigualdades inter- } \\
\text { regionais e divergências } \\
\text { crescentes nas suas respectivas } \\
\text { taxas de crescimento. }\end{array}$ & $\begin{array}{l}\text { Para além dos factores } \\
\text { mencionados em 3B, realça o } \\
\text { maior aproveitamento das } \\
\text { potencialidades endógenas, e a } \\
\text { promoção de iniciativas locais } \\
\text { através da cooperação, do } \\
\text { associativismo, e de parcerias } \\
\text { e pactos regionais, } \\
\text { complementados pela atracção } \\
\text { selectiva de investimentos } \\
\text { extra-locais com intuito de } \\
\text { fixar mais valor acrescentado } \\
\text { na localidade. }\end{array}$ \\
\hline $\begin{array}{l}\text { RACIONALI- } \\
\text { DADE }\end{array}$ & $\begin{array}{l}\text { Predominantemente } \\
\text { económica e produtivista. }\end{array}$ & $\begin{array}{l}\text { Predominantemente técnico- } \\
\text { científica e produtivista. }\end{array}$ & $\begin{array}{l}\text { Solidária, sustentada e } \\
\text { participada. }\end{array}$ \\
\hline $\begin{array}{l}\text { ACTOR } \\
\text { CHAVE }\end{array}$ & Empresário & Tecnocrata/Burocrata & $\begin{array}{l}\text { Líder político, empresarial } \\
\text { e/ou institucional regional e/ou } \\
\text { local }\end{array}$ \\
\hline $\begin{array}{l}\text { PRINCÍPIO } \\
\text { (RE)DISTRI- } \\
\text { BUTIVO }\end{array}$ & $\begin{array}{l}\text { Sendo de cariz liberal, esta } \\
\text { visão pouca ou nenhuma } \\
\text { importância dá às questões } \\
\text { distributivas. }\end{array}$ & $\begin{array}{l}\text { Predomina o princípio } \\
\text { redistributivo, embora a } \\
\text { vertente compensatória possa } \\
\text { ter um papel complementar. } \\
\text { Tem por objectivo principal } \\
\text { tornar mais equitativa a } \\
\text { distribuição inter-regional do } \\
\text { rendimento e do bem-estar, } \\
\text { independentemente da sua } \\
\text { distribuição social intra- } \\
\text { regional. Actua tipicamente no } \\
\text { sentido de cima para baixo. }\end{array}$ & $\begin{array}{l}\text { Predomina a vertente } \\
\text { compensatória, embora o } \\
\text { princípio redistributivo geral } \\
\text { continue a ter um papel } \\
\text { fundamental. Tem por } \\
\text { objectivo principal tornar mais } \\
\text { equitativa a distribuição inter- } \\
\text { regional do rendimento e do } \\
\text { bem-estar, realçando também a } \\
\text { sua distribuição social intra- } \\
\text { regional. Regiões ou } \\
\text { localidades devem ser } \\
\text { compensados através de } \\
\text { medidas específicas. Actua } \\
\text { tipicamente mais no sentido de } \\
\text { baixo para cima. }\end{array}$ \\
\hline
\end{tabular}

Continua... 
... Continuação.

\begin{tabular}{|c|c|c|c|}
\hline $\begin{array}{l}\text { PRINCIPAIS } \\
\text { POLÍTICAS }\end{array}$ & $\begin{array}{l}\text { Na delineação da sua política } \\
\text { geral, pouca importância dá a } \\
\text { medidas que visam suprimir } \\
\text { assimetrias territoriais, }\end{array}$ & $\begin{array}{l}\text { Redução das assimetrias inter- } \\
\text { regionais por via da limitação } \\
\text { das imperfeições do mercado } \\
\text { (em geral) e do mercado de } \\
\text { trabalho (em particular): } \\
\text { políticas realçam } \\
\text { investimentos nas } \\
\text { infraestruturas físicas e sociais } \\
\text { e a promoção de } \\
\text { deslocalização empresarial } \\
\text { para as regiões menos } \\
\text { favorecidas, privilegiando a } \\
\text { desconcentração espacial de } \\
\text { serviços públicos e parcerias } \\
\text { com grandes atores } \\
\text { empresariais. }\end{array}$ & $\begin{array}{c}\text { Para além das medidas } \\
\text { defendidas no modelo B, há } \\
\text { uma maior ênfase na } \\
\text { exploração sustentável de } \\
\text { recursos locais - físicos, } \\
\text { humanos, culturais e } \\
\text { patrimoniais - através de } \\
\text { políticas mais adaptadas às } \\
\text { condições e dotações locais, } \\
\text { com maior autonomia exercida } \\
\text { pelos agentes locais, bem } \\
\text { como o fortalecimento das } \\
\text { capacidades do poder local de } \\
\text { agir próactivamente. }\end{array}$ \\
\hline $\begin{array}{c}\text { PROBLEMA } \\
\text { FUNDAMEN- } \\
\text { TAL }\end{array}$ & $\begin{array}{c}\text { Desenvolvimento } \\
\text { espacialmente e socialmente } \\
\text { desigual, devido à } \\
\text { concentração do poder } \\
\text { negocial em poucas mãos, e ao } \\
\text { excessivo produtivismo, que } \\
\text { criam distorções estruturais e } \\
\text { promovem a desvalorização de } \\
\text { importantes fatores } \\
\text { socioculturais no } \\
\text { funcionamento de mercados } \\
\text { regionais/locais. }\end{array}$ & $\begin{array}{c}\text { Criação de dinâmicas de um } \\
\text { desenvolvimento dependente, } \\
\text { espacial- } \\
\text { mente e socialmente desigual, } \\
\text { devido a aplicação de modelos } \\
\text { inadaptados, decisões públicas/ } \\
\text { privadas longínquas e } \\
\text { subsídios estatais que } \\
\text { continuam a provocar } \\
\text { tecnocratismo e produtivismo } \\
\text { excessivos, promovendo } \\
\text { distorções no desenvolvimento } \\
\text { regional. Os objetivos } \\
\text { redistributivos podem colidir } \\
\text { com os da política } \\
\text { macroeconómica. }\end{array}$ & $\begin{array}{l}\text { O aumento da capacidade da } \\
\text { economia regional de enfrentar } \\
\text { os desafios do seu ambiente } \\
\text { externo (através de uma maior } \\
\text { afirmação regional, e um } \\
\text { aproveitamento de um leque } \\
\text { mais diversificado de recursos } \\
\text { e produtos regionais, tende a } \\
\text { consolidar ou mesmo reforçar } \\
\text { as assimetrias } \\
\text { socioeconómicas intra- } \\
\text { regionais, bem como a } \\
\text { estrutura/distribuição de poder } \\
\text { político/decisório e o recurso a } \\
\text { construção de competitividade } \\
\text { regional na base de relações e } \\
\text { práticas clientelares. }\end{array}$ \\
\hline
\end{tabular}

QUADRO 1 - DESENVOLVIMENTO REGIONAL: TIPOLOGIA DOS PRINCIPAIS PARADIGMAS/INFLUÊNCIAS ANALÍTICAS E QUADROS OPERACIONAIS.

FONTE: A problemática do Desenvolvimento Rural, Francisco Diniz e Chris Gerry (2002).

Numa perspetiva de marketing turístico, a realização de eventos pode ajudar a atenuar a sazonalidade (VIDAL, R. P.; RIEDL, M., 2016). A sustentabilidade deve ser uma prioridade. (SANTOS, R. A.; SANTOS, M. R., 2016). A definição de segmentos precisos ajuda a divulgar melhor o produto em nichos de mercado (PACHECO, I. C.; DEMCZUK, P. G., 2015).

Em Portugal, a oferta estava essencialmente constituída por 1300 estabelecimentos e 21,8 mil camas (INE, 2015). Analisando o número de estabelecimentos de turismo de habitação e de turismo no espaço rural constata-se um aumento consistente ao longo dos anos, com um crescente peso das casas de campo. Em 2015, as unidades de turismo no espaço rural e de habitação receberam 570 mil 
hóspedes, que deram origem a 1,3 milhões de dormidas e que geraram 60,1 milhões de $€$. A estada foi, em média, de 2,2 noites, e a taxa de ocupação foi 18,8\% (INE, 2015). A maioria dos hóspedes estavam sendo residentes em Portugal (62\%). No entanto, foram os estrangeiros que permaneceram mais tempo, registando uma estada média de 2,7 noites, face a 1,9 noites dos residentes em Portugal. O TOP 5 dos mercados externos foi constituído pela Alemanha, França, Espanha, Holanda e Reino Unido que, em conjunto, totalizaram 276,8 mil dormidas. Este número representou $67,2 \%$ do total das dormidas de estrangeiros.

Em termos de caracterização geográfica do espaço, o Parque Natural do Alvão é uma área protegida relativamente pequena, situada entre os concelhos de Vila Real e Mondim de Basto. Abrange 7200 ha de montanha sulcada por profundas linhas de água, ladeando a serra do Marão, que separa o Minho de Trás-os-Montes.

A Serra do Marão (FIGURA 1), estende-se entre o Rio Tâmega (Oeste), o Rio Corgo (Leste) o Rio Sordo (Norte) e o Douro (Sul). Tem uma geografia imponente, pelas suas abruptas encostas com grandes declives principalmente a voltada a Este para o eixo Vila Real -Santa Marta de Penaguião. Do ponto mais elevado (1415 m) se pode ver Vila Real, Serra do Alvão (Vaqueiro 1315 m) e a Sra. da Graça (920 m).

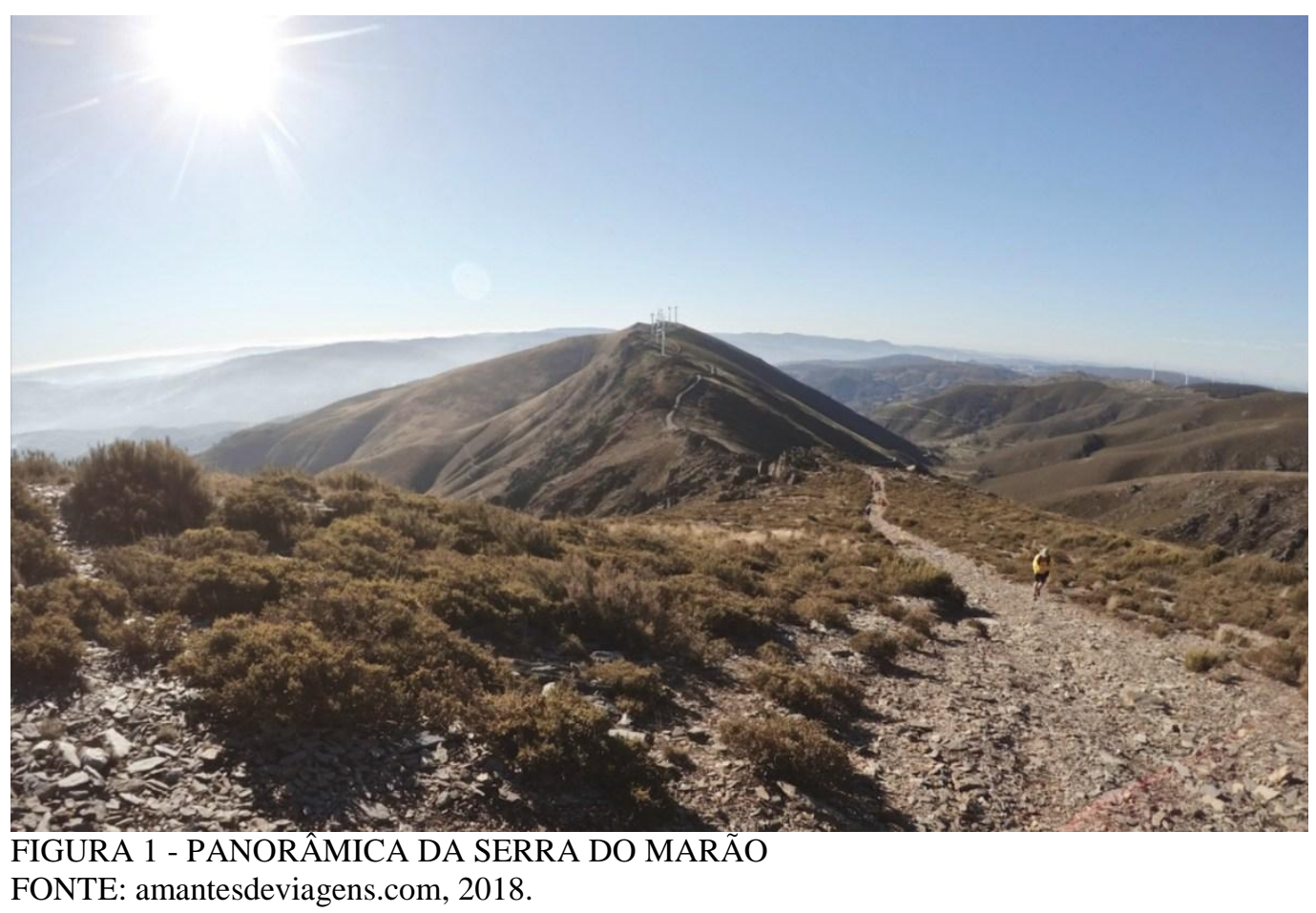




\section{DESENVOLVIMENTO DO ASSUNTO}

O presente estudo é de natureza exploratória e teve como intenção avaliar o impacto de uma unidade de Turismo Rural no desenvolvimento da região onde se insere. O objeto de estudo é o complexo de Turismo Rural da Casa da Cruz. O empreendimento localiza-se no Vale da Campeã, entre a Serra do Marão e o Parque Natural do Alvão (FIGURA 3), tendo iniciado atividade em 1988. A Casa da Cruz disponibiliza acomodações autossuficientes com uma varanda e acesso Wi-Fi gratuito. O alojamento fica a $14 \mathrm{~km}$ do Palácio de Mateus. Esta casa de férias possui 3 quartos e 3 casas de banho com uma banheira e um chuveiro. A casa de férias também providencia uma cozinha e uma casa de banho. A casa de férias dispõe de uma piscina exterior. A Casa da Cruz disponibiliza comodidades para churrascos e um terraço. $\mathrm{O}$ aeroporto mais próximo é o Aeroporto Francisco Sá Carneiro, a 67 km da propriedade, no Porto. Este é um dos aeroportos da Europa com maior crescimento, que é devido principalmente ao aumento da demanda de turistas para a citibreaks no Porto e Região Norte de Portugal (CARBALLO CRUZ; COSTA, 2014).

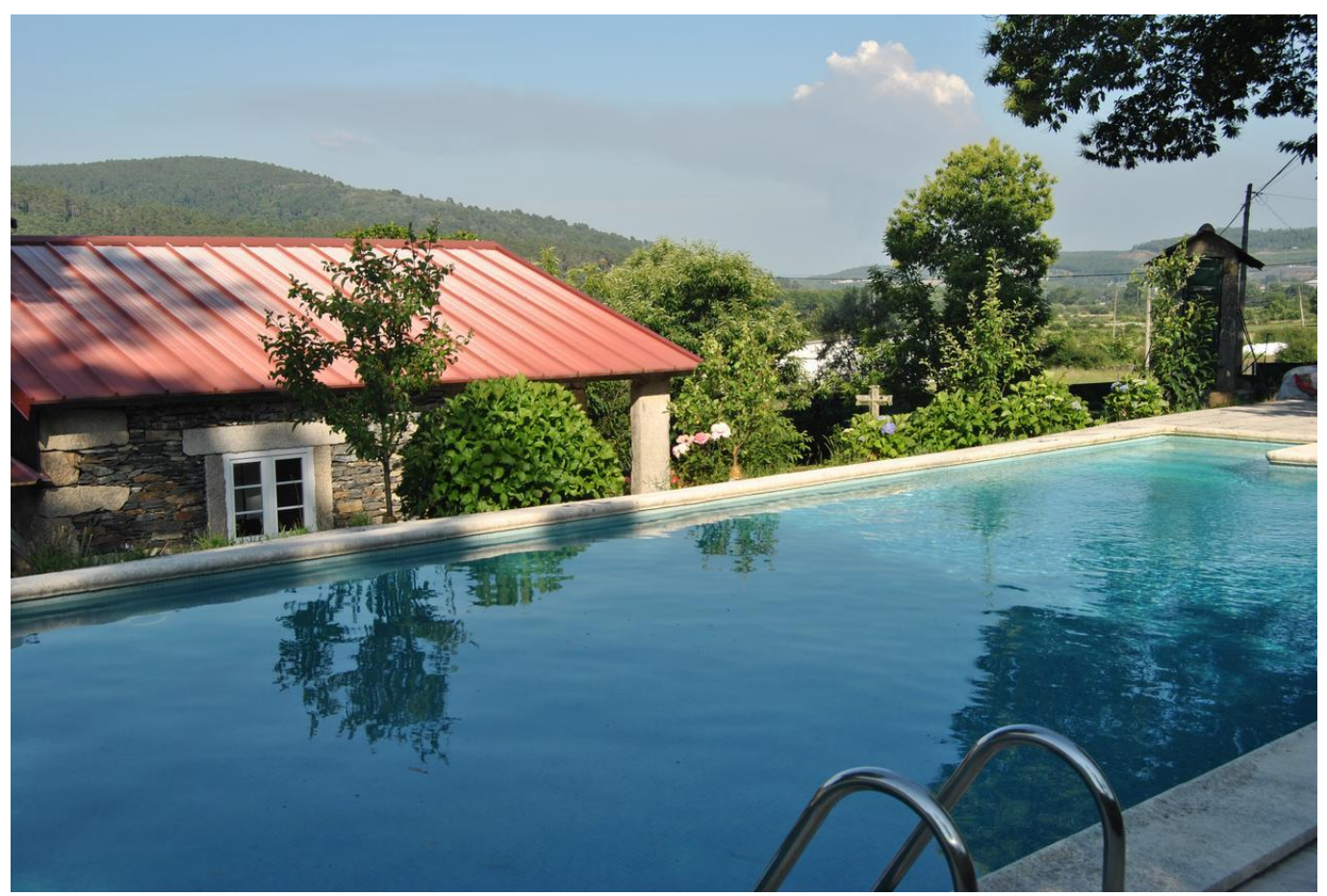

FIGURA 2 - CASA DA CRUZ

FONTE: Arquivo fotográfico do autor, 2018. 


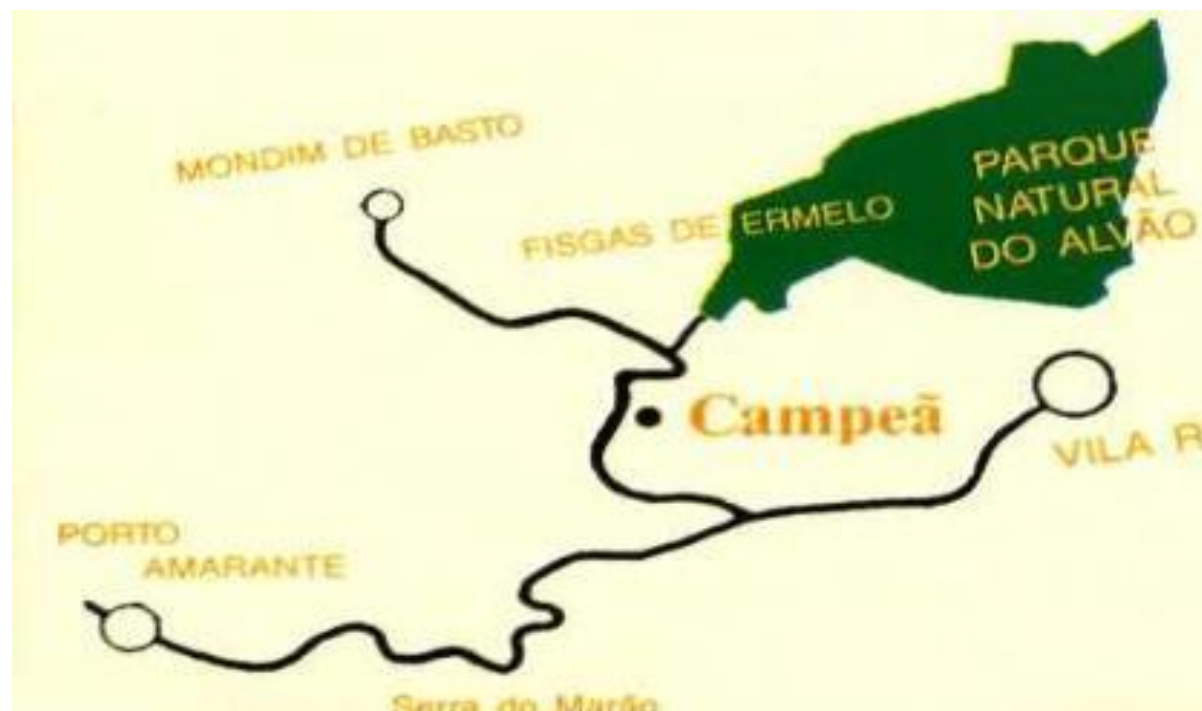

FIGURA 3 - MAPA DA REGIÃO

Fonte: Arquivo fotográfico do autor, 2018.

A população-alvo do estudo foi definida recorrendo aos contactos de visitantes da Casa da Cruz em 2009. Houve o cuidado de selecionar diversos turistas, de vários pontos do país, utilizando uma técnica de amostragem do tipo cluster, no sentido de conseguir obter alguma representatividade geográfica. Graças a um método de solicitação de colaboração muito assertivo, obteve-se uma taxa média de resposta que se situou em aproximadamente 90\%. 67 foram entrevistados.

Depois de recolhidos os questionários, procedeu-se à inserção dos dados numa base de dados. Estes foram processados através do recurso ao programa SPSS (Statistical Package for the Social Sciences). A análise dos dados recolhidos teve em atenção as não respostas, o quadro de distribuição de frequências, a representação gráfica da distribuição e a utilização das estatísticas adequadas ao resumo dos dados.

TABELA 1 - CARACTERIZAÇÃO DA AMOSTRA

\begin{tabular}{llr} 
Variáveis & Atributos & $\mathrm{n}$ \\
\hline Género & Feminino & 27 \\
& Masculino & 33 \\
Idade & -30 & 11 \\
& $31-40$ & 26 \\
& $41-50$ & 16 \\
Distrito & $51+$ & 7 \\
& Lisboa & 20 \\
& Porto & 15 \\
Profissão & Outros & 25 \\
& Quadros Superiores & 21
\end{tabular}




\begin{tabular}{llr} 
& Professores do Ensino Básico e Secundário & 11 \\
& Empregados dos serviços e comércio & 10 \\
& Quadros Médios e Técnicos Especializados & 9 \\
& Outros & 8 \\
\multirow{4}{*}{ Número de visitas à região } & 1 & 32 \\
& 2 & 11 \\
& 3 & 4 \\
\multirow{4}{*}{ Mês } & $4+$ & 2 \\
& Agosto & 29 \\
Dias na região & Julho & 11 \\
& Outros & 20 \\
\multirow{3}{*}{ Dimensão do grupo } & -2 & 15 \\
& $3-5$ & 24 \\
& $6+$ & 8 \\
& -2 & 12 \\
& $3-4$ & 21 \\
\hline
\end{tabular}

$\mathrm{N}=60$

FONTE: Pesquisa de campo, 2009.

Pela análise da amostra (TABELA 1) teve-se uma repartição quase igualitária entre o sexo masculino e feminino. No que respeita à estrutura etária, teve-se um predomínio da faixa dos 31 a 40 anos. Verificou-se também que não existiu ninguém abaixo dos 21 anos, o que denotou que não estava sendo um tipo de turismo, nem uma região, muito procurada por jovens adolescentes. Se os dados forem agrupados numa categoria acima de 41 anos tem-se o dado de $38,4 \%$.

No que respeita à proveniência, 58,3\% dos visitantes eram provenientes dos distritos de Lisboa e Porto. Quanto à profissão, o maior grupo correspondeu a quadros superiores, seguido da classe dos professores. As outras categorias que apareceram com relevo foram os quadros médios e técnicos especializados, bem como os empregados dos serviços, do comércio e administrativos. Apenas 3,3\% não estavam exercendo qualquer tipo de profissão. No que respeita às habilitações académicas, predominaram os licenciados, sendo que apenas $5 \%$ tinham menos do que o $9^{\circ}$ ano de escolaridade. $23 \%$ tinham uma formação até ao $12^{\circ}$ ano.

De seguida, procurou-se verificar outro aspeto importante: o número de vezes que estes turistas visitaram a região, bem como os meses do ano em que o fizeram e o número de dias que permaneceram na região. Os resultados revelaram que $65 \%$ das pessoas visitaram uma única vez a região e $23 \%$ vieram 2 vezes. $12 \%$ mais do que duas vezes. Outra variável é o mês em que os turistas visitavam a região. Desta forma foi possível verificar efeitos como a sazonalidade e a atração da região nos diferentes períodos do ano, nas diversas estações, climas e temperaturas. Os meses de Verão foram 
os mais escolhidos para as visitas. Em agosto, a afluência foi cinco vezes superior ao resto do ano, refletindo um hábito de forte impulso de férias neste período. $\mathrm{O}$ mês de fevereiro teve também algum destaque, aproveitando os turistas um período habitualmente classificado como mini-férias de Carnaval.

Para a verificação da duração da estadia, questionou-se: Quando visitou a região do Marão ficou, em média, quantos dias hospedado na região? Constatou-se o predomínio das visitas de 5 dias, havendo também muitas visitas de 48 horas. 80\% dos turistas haviam vindo por períodos de 2 a 5 dias. Verificou-se que os turistas aproveitavam períodos de fins-de-semana prolongados ou curtos períodos de férias para se deslocarem ao empreendimento. Acima de 5 dias não se verificaram frequências elevadas. A média da distribuição foi de 4,9 dias, sendo a moda nos 5. A mediana situando-se nos 3,5 .

Outro aspeto importante foi a dimensão do grupo. Saber o número de elementos que o constituem é fundamental para definir o perfil do turista que visitava o empreendimento. Concluiu-se assim que a maioria dos agregados que visitavam o Marão era compostos por 2 a 3 pessoas. Notou-se também que ninguém visitou sozinho a região. Isto revelou que este era um turismo de pessoas, de grupos e não de negócios.

Depois de verificação de variáveis mais quantitativas, foram abordados temas mais qualitativos. Assim, importava saber se os turistas apreciaram a sua estadia na região, questionando aspetos diversos como a paisagem, a gastronomia, o alojamento e as atividades de lazer (TABELA 2).

TABELA 2 - RESULTADOS DA AMOSTRA

\begin{tabular}{llr} 
Variáveis & Atributos & $\mathrm{n}$ \\
\hline Paisagem & Excelente & 27 \\
Gastronomia & Boa & 21 \\
& Boa & 18 \\
Alojamento & Razoável & 19 \\
& Fraca & 7 \\
Actividades de lazer & Excelente & 16 \\
& Bom & 18 \\
& Razoável & 12 \\
Preço & Excelente & 5 \\
& Bom & 12 \\
& Razoável & 15 \\
& Excelente & 9 \\
& Bom & 19 \\
& Razoável & 16
\end{tabular}




\begin{tabular}{llr} 
Intenção de recomendação & Sim & 52 \\
& Não & 6 \\
\hline
\end{tabular}

FONTE: Pesquisa de campo, 2009.

A maioria dos visitantes atribuiu nota máxima à paisagem da região, verificando-se $98 \%$ se agrupados os 2 níveis mais elevados. Constatou-se assim que a paisagem ficou definida claramente como um poderoso indicador de qualidade desta região. Em relação à gastronomia, verificou-se igualmente níveis elevados de satisfação, ainda que relativamente menores quando comparados com a paisagem. A moda situa-se na categoria "Razoável". Agrupando os dois maiores níveis de satisfação, concluiu-se que $76 \%$ dos visitantes estavam satisfeitos com a gastronomia. Verificou-se uma repartição entre os níveis "Razoável", "Bom" e "Excelente". A moda ficou no nível "Bom". O Alojamento foi classificado de razoável a excelente. Registrou-se, contudo, a ausência dos níveis "Fraco" e "Mau", os mais baixos.

Da análise respeitante às atividades de lazer, viu-se o predomínio dos níveis "Razoável" e "Bom". Apenas 10\% se demonstraram muto satisfeitos (excelente). Reforçou-se que esta estava sendo uma área ainda incipiente na região, a necessitar de mais e melhor oferta de forma a ser mais agradável para os turistas. Tornando-se importante que eles tenham animação que os retenha, quer mais contentes, quer durante um período de estadia mais alargado. Outro aspeto de realce foi que pela primeira vez apareceram referidas as categorias de mais baixo nível de satisfação.

Relativamente ao preço, constatou-se que $18 \%$ das pessoas ficaram satisfeitas com o preço, sendo que $4 \%$ não gostaram muito. A grande maioria aceitou o preço como justo.

Outro aspeto decisivo foi a recomendação do destino turístico. Considerando que a satisfação do cliente tende a levar à recompra, aceitação de outros produtos ou recomendação, o conhecimento dos fatores que afetam a satisfação e a fidelidade é essencial para empresas que atuam em mercados competitivos. Para avaliar este índice colocou-se a questão para saber da intenção de recomendação. $86 \%$ dos visitantes recomendaram o destino turístico.

Uma vez que uma das variáveis que se pretendeu explicar foi se havia visitado ou não o Marão, pôde ser aplicado o modelo Probit ou Logit, os quais proporcionaram resultados idênticos. Como o número de visitas apresentou dados de contagem, 
apresentou-se igualmente um modelo de contagem, mais especificamente o modelo de Poisson. No sentido da verificação dos resultados da estimação, as diferentes variáveis foram quantificadas do seguinte modo: Visita ao Marão (VM); Número de vezes que visitou o Marão (NV); Número de acompanhantes (NA); Tempo de permanência (TP).

TABELA 3 -RESULTADOS DOS MODELOS

\begin{tabular}{|l|r|r|r|}
\hline & \multicolumn{1}{|c|}{ NV } & NA & \multicolumn{1}{c|}{ TP } \\
& Poisson & Poisson \\
\hline Constante & 1,565 & 0,742 & $1,255^{* *}$ \\
& $-1,377$ & $-0,58$ & $-2,491$ \\
\hline Género & $--0,445$ & 0,015 & $-0,204$ \\
& $(-0,776)$ & $-0,03$ & $(-0,990)$ \\
\hline Idade & $-0,009$ & 0,001 & $-0,012$ \\
& $(-0,431)$ & $-0,063$ & $(-1,349)$ \\
\hline Distância & $-0,003 *$ & 0 & $0,002^{* * *}$ \\
& $-1,873$ & $(-0,270)$ & $-3,295$ \\
\hline Educação & $-0,329$ & 0,007 & $-0,034$ \\
& $(-1,550)$ & $-0,039$ & $(-0,400)$ \\
\hline Valor da função de verosimilhança & $-45,84$ & $-70,3$ & $-101,92$ \\
\hline Qui-quadrado (nível de significância) & 13,21 & & 12,37 \\
& $-0,01$ & $-0,015$ \\
\hline Teste de sobredispersã, $\mathrm{g}=$ um(i) - estatística t & 1,061 & 1,506 \\
\hline Teste de sobredispersã, $\mathrm{g}=$ um(i) ${ }^{2}-$ estatística & 1,321 & 1,344 \\
\hline
\end{tabular}

Notas: Entre parâmetros estatística Z (t); * Estatisticamente significativa a 10\%; ** Estatisticamente significativo a $5 \% ; * * *$ Estatisticamente significativa a $1 \%$

FONTE: Pequisa de campo, 2009.

Verificou-se que as regressões NV e TP foram globalmente significativas a 5\% de nível de significância (TABELA 3). Para este resultado, em termos de variáveis individuais, contribuiu a distância, a única que foi estatisticamente significativa. Estes resultados indicaram que o número de visitas, o número de acompanhantes e o tempo de permanência, não foram influenciadas pela diferença de género, idade e nível de educação. Por outro lado, o número de visitas variou de forma inversa com a distância e o tempo de permanência aumentando com a distância. Ou seja, "quanto mais perto", mais vezes e mais curta a permanência. Desta forma considerou-se poder concluir da necessidade de facilitar e melhorar a rede de transportes devido à distância tempo e criar condições para que os de longe permaneçam mais dias. 


\section{CONCLUSÃO}

O presente estudo consistiu em abordar os modelos de desenvolvimento baseados em turismo, adequados a áreas rurais, interiores e periféricas, numa lógica de estudo de caso. Nas áreas rurais, constatou-se existir alguns produtos turísticos inovadores, indutores de desenvolvimento endógeno que proporcionam ao turista experiências criativas, com o seu envolvimento e participação ativa nas atividades oferecidas pela comunidade.

Efetuou-se uma caracterização do Turismo no Espaço Rural, enfocando numa unidade turística particular do Marão (Portugal).

Considerou-se ter sido possível efetuar uma recolha e análise de dados primários que permitiu tirar algumas conclusões que pareceram pertinentes para a gestão do turismo, particularmente, no que diz respeito às estratégias e ações de marketing neste sector.

Verificou-se haver uma satisfação dos visitantes em relação à experiência no seu global. No que respeita ao lazer e à animação turística seria necessário desenvolver um trabalho capaz de levar simultaneamente à interpretação do espaço envolvente e ao desenvolvimento de atividades físicas e intelectuais que provoquem um aumento da satisfação do turista. Pareceu que a disponibilização de um calendário de eventos de projeção internacional seria importante para reforçar as motivações e promover a fidelização do turista (no caso de eventos regulares). Esta realidade podendo ser observada em destinos concorrentes de Portugal. Estas medidas possibilitariam também captar o crescente volume de tráfego de aviões e passageiros no Aeroporto do Porto, próximo da Serra do Marão e do Douro.

\section{REFERÊNCIAS}

CARBALLO-CRUZ, F.; COSTA, V. Fatores de sucesso dos aeroportos regionais: o caso do aeroporto do Porto. Tourism \& Management Studies, 10 (1), p. 37-45, 2014.

CAVACO, C. Turismo rural e desenvolvimento local. Turismo e geografia-reflexões teóricas e enfoques regionais. São Paulo: Hucitec, 1996, p. 94-121. 
DIMITROVSKI, D. D.; TODOROVIĆ, A. T.; VALJAREVIĆ, A. D. Rural tourism and regional development: Case study of development of rural tourism in the region of Gruța, Serbia. Procedia Environmental Sciences, 14, 201, p. 288-297, 2012.

DINIS, M. G. F.; COSTA, C.; PACHECO, O. Indicadores estatísticos do turismo em portugal. Exedra: Revista Científica, (1), p. 49-69, 2017.

DINIZ, F. Crescimento e Desenvolvimento Económico: Modelos e Agentes do Processo. Lisboa: Edições Sílabo, 2006.

DINIZ, F.; GERRY, C. A problemática do desenvolvimento rural. Compêndio de Economia Regional, p. 535-570, 2002.

EURICO, S. T.; OLIVEIRA, F. M. F. Sustainable tourism development of rural destinations: the Schist Villages, Portugal. Planning for Tourism: Towards a Sustainable Future, 169, 2015.

KASTENHOLZ, E. 'Cultural proximity'as a determinant of destination image. Journal of Vacation Marketing, 16 (4), p. 313-322, 2010.

KASTENHOLZ, E.; LIMA, J. The integral rural tourism experience from the tourist's point of view - a qualitative analysis of its nature and meaning. Tourism \& Management Studies, n. 7, p. 63-66, 2011.

KLEIN, A. Turismo rural pedagógico sob a perspectiva da multifuncionalidade da agricultura: experiências no sul do Brasil. Pasos - Revista de Turismo y Patrimonio Cultural, v. 12, n. 3, p. 581-595, 2014.

MARQUES, C. D. C. P. Emotions, Motivations and Destination Positioning. CETRAD - Centro de Estudos Transdisciplinares para o Desenvolvimento, 2005.

MATEUS, A. O mundo rural e o desenvolvimento económico e social de Portugal: Uma Agenda para o futuro. Câmara Municipal Idanha-a-Nova, 2017.

NEVES, A. Estudo de caracterização do turismo no espaço rural e do turismo de natureza em Portugal. Lisboa: IESE, DGADR, 2017.

PACHECO, I. C.; DEMCZUK, P. G. O mototurismo e o desejo de viajar no estilo de vida Harley Davidson: um estudo de caso sobre o Chapter HOG-The One Curitiba (Paraná, Brasil). Turismo e Sociedade, v. 8, n. 2, 2015.

PATO, M. L. J. As dinâmicas do Turismo no Espaço Rural (TER) - Implicações em termos de Desenvolvimento Rural, Unpublished $\mathrm{PhD}$ thesis, Aveiro, University of Aveiro, 2012.

RIBEIRO, M. Espaços rurais como espaços turísticos: reflexões em torno da construção da oferta de turismo em espaço rural, em Portugal. In: PORTELA, J.; CALDAS, J. (orgs.) Portugal Chão. Oeiras: Celta Editora, 2003. p. 199-215. 
SANTOS, R. A.; SANTOS, M. R. Sustentabilidade e Hotelaria: Um Estudo de Caso no Município de Nova Iguaçu, Rio de Janeiro, Brasil. Turismo e Sociedade, v. 8, n. 3, 2016.

SILVA, L. A procura do turismo em espaço rural. Etnográfica, 11 (1), p. 141-163, 2007.

TRINDADE, L. Uma parceria estratégica a favor da competitividade no Turismo. Economia \& Prospectiva, 1(4), p. 33-38, 1998.

TURISMO DE PORTUGAL. (2015). Turismo 2020 - Plano de Ação para o desenvolvimento do turismo em Portugal. Turismo de Portugal. Acedido a $14 \mathrm{de}$ março de 2015. Disponível em:

<http://turismo2020.turismodeportugal.pt/fotos/editor2/documentos/Turismo2020_PL ANO_DE_ACAO.pdf $>$.

VIDAL, R. P.; RIEDL, M. A influência do turismo de eventos na Região das Hortênsias, Rio Grande do Sul, (Brasil): o caso do evento Natal Luz de Gramado. Turismo e Sociedade, v. 9, n. 3, 2016.

Recebido em: 17-03-2018.

Aprovado em: 16-03-2018.

Versão finalizada em: 05-12-2018. 